\title{
Medical professor as a patient
}

Kyung Hye Park ${ }^{1,2}$

${ }^{1}$ Department of Medical Education, Yonsei University Wonju College of Medicine, and ${ }^{2}$ Department of Emergency Medicine, Wonju Severance Christian Hospital, Wonju, Korea

I underwent a right thyroidectomy. The biopsy came back as cancer. In this paper, I would like to reflect on my experience as an emergency physician and professor who teaches medical communication and patient safety. I had taken a cervical spine magnetic resonance imaging once, back in my mid-30s, because my right arm had become numb. A simple cyst was incidentally discovered on my right thyroid. The endocrinology doctors assured me there was no cause for concern, so I went on with my life. By the time I turned 40 in early 2017, I decided to get a full medical examination. The cyst that I had forgotten about had changed into a $2.9 \times 3.6 \mathrm{~cm}-$ sized oval isoechoic mass with an internal cystic portion. The examination center suggested that I have an ultrasound exam in 1 year.

One year later, I received a thyroid sonography again. Nothing turned up, and I got another ultrasound a year later, in January 2019. The result was "36 mm partially cystic nodule with suspicious feature in right lobe, category IV, intermediate suspicion, indeterminate lymph node at right level III." I was scared because the word “malignancy" usually follows the word "suspicious." And "category IV"? What kind of category was that? Categories are also expressions that are used to classify the state of cancers, so I was terrified. The health promotion center told me that they would schedule an appointment to get a biopsy for nodule through a fine needle aspiration (FNA) biopsy. The professor of surgery skillfully and quickly completed the FNA. Regardless of the biopsy, he had recommended surgery because of the large size. Biopsy results usually come out about a week later in outpatient care, but in my nervous state I logged into the electronic medical record system every day. That year, I had responsibilities for the courses in medical communication and patient safety, and the new head of the clinical competency development center, as well as a myriad of other tasks. Furthermore, I was worried whether my voice would be okay after the surgery. I could see my biopsy results before my scheduled outpatient care date. The results said "category I (the Bethesda System): nondiagnostic/unsatisfactory, virtually acellular specimen/paucicellular smear." I was
Received: March 4, 2020 • Revised: March 18, 2020 • Accepted: March 23, 2020 Corresponding Author: Kyung Hye Park (https://orcid.org/0000-0002-5901-6088) Department of Medical Education, Yonsei University Wonju College of Medicine, 20 Ilsan-ro, Wonju 26426, Korea

Tel: +82.33.741.0242 Fax: +82.33.742.5034 email: erdoc74@gmail.com
Korean J Med Educ 2020 Jun; 32(2): 151-154.

https://doi.org/10.3946/kjme.2020.163

eISSN: 2005-7288

(C) The Korean Society of Medical Education. All rights reserved. This is an open-access article distributed under the terms of the Creative Commons Attribution Non-Commercial License (http:// creativecommons.org/licenses/by-nc/3.0/), which permits unrestricted non-commercial use, distribution, and reproduction in any medium, provided the original work is properly cited. 
relieved that the number "IV" had changed to the number "I," but he suggested that we do another FNA in 6 months.

When I got back to my office, I looked up the thyroid nodule treatment guideline. It stated that I needed to repeat the biopsy, as my biopsy results came out as unsatisfactory for a low-risk nodule based on its ultrasound characteristics [1]. My mind was at ease, as he was treating me in accordance with the guideline.

I got another biopsy done in August. The results said "category III (the Bethesda System): atypia of underdetermined significance/follicular lesion of undetermined significance, BRAF gene mutation test is recommended." The words "atypia" and "underdetermined" were worrisome. According to the Bethesda System for reporting thyroid cytopathology, the progress toward malignancy was $10 \%-30 \%$ in the case of category III [2]. He told me that the BRAF gene mutation examination does not significantly help in definite diagnosis and that he did not recommend it [3], but he did recommend surgery again. It was not urgent, so I decided to have it done in January 2020, when the national examination for fourth-year medical students and the early admissions period had ended. I was more worried about making sure that my work would not pile up than the surgery itself. In January, I was hospitalized for thyroidectomy. The surgery resident came to see me the day before the surgery. He knew that I was a medical professor and asked me how he should explain things. I was suddenly reminded of a situation in my medical communication class when my students asked me how they could explain things when doctors came in as patients. At that time, I recommended they should first ask how and what the patient want. I told him to explain things as he would to any other patient, as I knew very little about thyroid surgery. He told me that because the mass was on the right side, only right thyroid and isthmus would be removed. After the surgery, I would need to take thyroid hormone medication, and then they would decide whether to prescribe more based on my thyroid hormone levels. I was happy to hear that they could do a partial thyroidectomy and that I might not have to take medication for the rest of my life. However, though my right thyroid was to be removed, I had an irrational fear that they would take out the left one by mistake. This was because I know some cases where the surgery locations had been switched unintentionally while teaching patient safety course.

It felt strange to be brought in looking at the ceiling as a patient. I was a little nervous because they did not mark my right neck as I had seen in the patient safety textbook. However, both the surgery resident and the surgery room nurses asked me a few times which thyroid it was, and that put me a little at ease. The anesthesiology professor greeted me warmly. He showed me the endotracheal tube that he would use on me, telling me not to worry because surgeries are conducted with an electrophysiologic intraoperative neural monitoring device connected to the endotracheal tube, ensuring that the recurrent laryngeal nerve is well preserved [4]. In that moment, one of the many concerns I had was solved, and I was able to be sedated in a good mood. When I opened my eyes, I was in a patient's room. I did not remember the recovery room and I slept until the evening. I woke up to have my dinner, but perhaps because they opened my neck area, it was very difficult for me to lift my neck, get up, talk, or swallow food. It was extremely uncomfortable, as I had to wear a Hemovac on the area that underwent surgery until the day I was discharged. I had to ask my mother to lift me up, and ate porridge during hospitalization.

I was discharged on the fourth day after my surgery without hearing of my biopsy results. I asked a friend of mine, a professor in another department, to look at my 
biopsy results. "Thyroid gland, right, lobectomy with central compartment neck node dissection." They must have made an incision in the neck node in case it was cancer. Luckily, it had not metastasized. But there were words that suddenly caught my eye: "papillary thyroid carcinoma, subtype: follicular variant (encapsulated with invasion).” In a word, it was cancer. I was suddenly reminded of the term "5-year survival." Thyroid cancer is common and they say it is not really a serious cancer, but it still felt strange. Were there subtypes of papillary thyroid cancer? When I looked it up, follicular variants were the most common form of papillary carcinoma, and the article said that because of the good prognosis, it could be called a neoplasm and not a malignancy [5]. I was relieved to hear that. Was this the silver lining?

On the first day of outpatient care following the surgery, he said that it was fortunate that a cancer with a good prognosis was discovered, and that there were no further treatments. My thyroid hormones were within the normal range.

I stood in front of the classroom in my first lecture after my 3-week sick leave. My voice had not yet fully recovered, and my throat hurt the more I talked. My voice has almost returned to normal now that 2 months have passed, but the pain returns the more I talk. Even without direct damage to the recurrent laryngeal nerve, the doctors say the symptoms of difficulties with speaking and swallowing persist for a while but improve as time goes by [6].

I did not think much of thyroid cancer either when I studied it as a medical student or when I saw patients. I felt that I was able to identify and understand more of the words that the doctors said to me during the clinical decision-making process because I was a fellow doctor. A lay person without medical knowledge may question why such decisions were made and why such words were spoken. In addition, I think I had additional worries as a doctor and a medical educator that other people would not.

I believe this experience as a patient will aid me in teaching medical communication or patient safety. I can explain how nervous a patient gets, and how every patient has a unique illness experience even if they have the same diagnosis. I deeply reflected on my experience while writing this essay. Thus, I'm planning to make students write about their illness experiences to promote deep understanding of patients' feelings, similar to the study of Hwang et al. [7].

\section{ORCID:}

Kyung Hye Park: https://orcid.org/0000-0002-5901-6088

Acknowledgements: None.

Funding: None.

Conflicts of interest: No potential conflict of interest relevant to this article was reported.

Author contributions: All work was done by Kyung Hye Park.

\section{References}

1. Wong R, Farrell SG, Grossmann M. Thyroid nodules: diagnosis and management. Med J Aust. 2018;209(2): 92-98.

2. Cibas ES, Ali SZ. The 2017 Bethesda system for reporting thyroid cytopathology. Thyroid. 2017;27(11): 1341-1346.

3. Lubitz CC, Zhan T, Gunda V, et al. Circulating BRAFV600E levels correlate with treatment in patients with thyroid carcinoma. Thyroid. 2018;28(3):328-339.

4. Randolph GW, Dralle $\mathrm{H}$; International Intraoperative Monitoring Study Group, et al. Electrophysiologic recurrent laryngeal nerve monitoring during thyroid and 
parathyroid surgery: international standards guideline statement. Laryngoscope. 2011;121 Suppl 1:SI-SI6.

5. Haugen BR, Sawka AM, Alexander EK, et al. American Thyroid Association guidelines on the management of thyroid nodules and differentiated thyroid cancer task force review and recommendation on the proposed renaming of encapsulated follicular variant papillary thyroid carcinoma without invasion to noninvasive follicular thyroid neoplasm with papillary-like nuclear features. Thyroid. 2017;27(4):481-483

6. Kim H, Keum BR, Kim GH, et al. Analysis of voice and swallowing symptoms after thyroidectomy in patients without recurrent laryngeal nerve injury in early postoperative period. J Korean Soc Laryngol Phoniatr Logop. 2016;27(2):108-113.

7. Hwang K, Fan H, Hwang SW. Writing about an experience of illness in medical students. Adv Med Educ Pract. 2013;4:151-155. 